\title{
Online access to higher education on YouTubeEDU
}

\author{
Hsin-liang Chen and Sarah Burns Gilchrist \\ School of Library and Information Science, Indiana University, Indianapolis, \\ Indiana, USA
}

\begin{abstract}
Purpose - The purpose of this one-year longitudinal study is to examine the usage and production of educational videos on YouTubeEDU, an open, video-sharing, educational area of YouTube established in 2009 and used primarily by institutions of higher education. The aim of the YouTubeEDU project is to provide free global access to higher education videos. Analysis from a library science perspective is valuable to further development of YouTubeEDU.

Design/methodology/approach - From August 2010 to July 2011, the top 50 video clips were recorded monthly. YouTubeEDU loosely arranged clips according to the number of site visits and classified them into 13 disciplines: business, education, engineering, fine arts and design, health and medicine, history, humanities, journalism and media, law, literature, mathematics, science, and social science. Analysis of subject area and content correspondence was conducted using YouTubeEDU-assigned, creator-defined, and study-specific attributes.

Findings - The majority of top videos per month were university public relations materials. Overall, 40 percent of the videos were academically-oriented; English is the predominant language. Even some videos contributed by non-English-speaking higher education institutions were in English. The researchers also discovered misclassification of videos in several disciplines.

Research limitations/implications - Based on the researchers' monthly observations, future collaboration with the YouTubeEDU project is needed to collect comprehensive data regarding worldwide visitor traffic and higher education video contributions.

Originality/value - Many areas needed improvement in the YouTubeEDU project; the proposed changes would ensure that the quality and utility of videos meet the standards of higher education institutions while embracing the needs of global learners.
\end{abstract}

Keywords Open access, E-learning, Social media, Higher education, YouTubeEDU, Pedagogical design, Learning

Paper type Research paper

\section{Introduction}

Internationally, higher education has adopted web-based techniques to enhance teaching and learning practice (Bonk, 2009). YouTube, a free video-sharing website, is one of the web-based technologies which has been widely used by individual users and organizations. On March 25, 2009, over 300 universities and colleges around the world partnered with YouTube to launch YouTubeEDU (Kincaid, 2010). On YouTubeEDU, learners from all over the globe can view free videos in seven languages from worldwide universities, colleges, and learning institutions. During the first year, the number of uploaded videos reached over 65,000. Although distance education is not a new concept, since the advent of the worldwide web, information is available more readily to those with the appropriate resources and technology. YouTubeEDU allows internet users to find credible sources of information from internationally-known institutions of higher education.

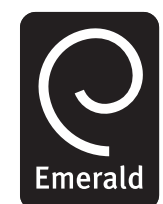

New Library World Vol. 114 No. 3/4, 2013 pp. 99-109 
NLW

$114,3 / 4$

100
The purpose of this study was to examine the current potential of YouTube EDU and to develop future applications of this resource. As the video collection of YouTubeEDU grows, measuring the impact of this resource is necessary. Throughout the course of this research the authors have asked whether contributions to YouTubeEDU could be classified as academically oriented; whether disparities exist between contributions from different academic disciplines; and whether higher education institutions will increase contributions to online learning sources.

\section{Literature review}

Higher education in the open access era

Open access courses were initiated on a grand scale by the Massachusetts Institute of Technology (MIT). In her book DIY U, Kamenetz (2010, p. x) mentions that MIT took its courses online in 2001 and had more than 63 million views by 2009. Kamenetz (2010, p. 90, p. 87) also investigates the Open Learning Initiative at Carnegie Mellon and an open course public high school in Utah. Although positive outcomes were reported in all cases, the majority of these open access online courses concern science and maths rather than the humanities. It is implied that this deficit reflects the more fluid and changing nature of the humanities. Hard science and mathematics deal with facts; when they do change, they build upon a solid foundation. Kamenetz (2010) suggests that students will choose to replace all or part of their higher education with online open access courses; she also believes that the humanities courses require more human interaction and, consequently, more time in the classroom. Gauntlett (2011) echoed Kamenetz's ideas and suggested that gatekeeper-free platforms such as YouTube allow users to connect their creative works directly to education and workplace. Lange (2012) agreed with this DIY approach as a vital element for human development.

Knowledge production, or empirical knowledge, relies on the consumption of scholastic knowledge. The two processes are intertwined and "the university [...] continuously expands its territory by adapting and assimilating the empirical into the scholastic" (Kamenetz, 2010, p. 7). Additionally, knowledge is a pathway to personal success (Kamenetz, 2010). The current system of higher education validates knowledge with certificates or degrees. According to Lewin's (2011a, b, c, d, e) series of articles on online education, Straighterline is one for-profit online learning company. Students pay to take online courses that may transfer to institutions of higher education to help complete or initiate a degree (Lewin, 2011a, b). Non-profit learning institutions have also appeared: Peer 2 Peer University, University of the People, Western Governors University, and Learning Counts (Kamenetz, 2010; Lewin, 2011c, d, e). These initiatives promote student-guided paths to knowledge, yet few of them take advantage of video courseware such as YouTubeEDU.

Many scholars agree that online learning has become an integral part of higher education, yet they differ regarding the percentage of online courses necessary for today's students. Cao and Hong (2011) uncovered four factors that influence social media utilization in college teaching: faculty personal social media involvement; external pressures from peers, supervisors, students, and their employment; expected benefits; and perceived risks. Their belief that "social media tools may not necessarily be suitable and fruitful for every faculty member or every subject" is also shared to some degree by Kamenetz (Cao and Hong, 2011, p. 304). Chelliah and Clarke (2011, p. 276) found that there is a shift in how students learn and communicate and that 
"[t]echnology by itself cannot change the nature of classroom instruction unless educators are able to evaluate and integrate the use of that technology into the curriculum". One of the benefits of our increased access to information is the ability to tailor learning experiences to each student's needs.

The applications of digital video content for personal enrichment are numerous. At least one institution (University of the People) has begun to offer open-access learning and degrees to online scholars (Lewin, 2011c). In addition, Strom (2012) reported that many public schools in the US are no longer banning access to YouTube for classroom

Online access to higher education instruction and that YouTube has created a special YouTube portal for K-12 students. These changes are indications of the YouTubeEDU effect on education at all levels.

Higher education institutions worldwide have allocated substantial resources to facilitate the development of online education for diverse populations. For example, Markoff (2012) reported that Stanford University partnered with the University of California-Berkeley, University of Michigan, University of Pennsylvania, and Princeton University to launch an interactive online learning system with \$16-million in venture capital support. The non-profit group TED (Technology, Entertainment, Design) launched a new website, TED-Ed, where instructors can use interactive videos to enhance their online instructional activities (TED-Ed., 2012). As of April 25, 2012, TED's open access videos are classified into nine disciplines. Major research effort has focused on the development of more effective learning systems and platforms for the purpose of open access education; consequently, attention to the content of learning materials and to media is needed to ensure the quality of online education.

\section{Management of YouTubeEDU collections}

The selection of media for online instruction has been identified by many instructional designers as a key component of online learning systems (Andrews and Goodson, 2011; Hirumi and Kidney, 2011; Schiffman, 2011). The emphasis on the selection and use of instructional media parallels the practice of library collection development and management. Collection development and management is important to the success of any kind of resource (Orcutt, 2010; Gregory, 2011).

Additionally, review of the available YouTube collections can indicate the level of participation from those higher-education institutions. Leung (2009) studied user-generated content on the internet at the individual level. The results of her study reaffirmed that content contributors were motivated by obtaining recognition online, as well as by the freedom to express their own unique viewpoints on various issues. The YouTubeEDU project offers a unique research opportunity to examine the issue of motivation for contributing at the institutional level.

In the developmental stage of the MIT OpenCourseWare (OCW) project, one major challenge was obtaining publication permission for course content and materials (Lerman and Miyagawa, 2003). As of March 2012, the OCW project offers over 2000 courses in 36 subject areas (MIT OpenCourseWare, 2012). The philosophy of content development for the OCW project is based on MIT's available undergraduate and graduate courses. According to the OCW site, there were 90 million visitors between January and October of 2011 (MIT OpenCourseWare, 2012). If the YouTubeEDU project wants success rates similar to those of the OCW project, an examination of its collections and their organization is necessary and important. 
NLW

$114,3 / 4$

102
In order to understand the strength and growth of a collection, librarians examine collections by classification (e.g. history, languages, mathematics) and time-based factors (e.g. publication dates, monthly circulation numbers) (Lyons, 2010; Gregory, 2011). Following collection development guidelines, the authors evaluated the top 50 videos from YouTubeEDU's video collection on a monthly basis according to YouTube's classifications. Using this fundamental evaluation mechanism, the goal of this project was to discover the core content characteristics of YouTubeEDU's video collection.

During the course of data collection, patterns became apparent; while continuing to collect information the authors were able to provide more detailed answers for the preliminary research questions. The findings uncovered the frequency of contributions to YouTubeEDU by individual institutions; the dominant language (English) and the appearance of secondary languages (Russian, Italian, Spanish, Hebrew, French); the most popular subjects and academic value of video submissions; the accuracy of categorization (using metadata) by YouTubeEDU and the host institution; and a variety of qualitative characteristics. The research questions were deliberately broad in order to provide holistic analysis of YouTube EDU and the video submissions.

\section{Research questions}

- What are the characteristics of the most-viewed videos at YouTubeEDU?

- What are the subject and disciplinary distributions of the most-viewed videos?

\section{Research methods}

The data collection process occurred between August 1, 2010 and July 1, 2011 on the YouTubeEDU project website. The YouTubeEDU project did not have its own uniform resource locator (URL). In order to reach the first webpage of the project, the authors went to the YouTube website and clicked on "Browse" and then chose the "Education" category. The "YouTubeEDU" label was nested under the "Education" category. During the study there were 13 disciplines outlined by YouTube: business, education, engineering, fine arts and design, health and medicine, history, humanities, journalism and media, law, literature, mathematics, science, and social science. At the end of July 2011, YouTube changed this arrangement and removed both the label "YouTubeEDU" and the 13 disciplines from its website.

On the first day of each month, the top fifty most-viewed videos were collected from each of the 13 disciplines. YouTubeEDU displayed the most-viewed videos as a default. In addition, the top 50 most-viewed videos were collected of "all time" each month as benchmarks.

During the course of this evaluation, observers continuously collected, reported, and discussed data. Although data collection was constrained to specific dates and times each month (to ensure a modicum of consistency), the analysis occurred as pertinent details were revealed. A qualitative analysis was used to define and track areas of focus. Rank and viewership numbers were tracked over time and recorded in a spreadsheet. Institutions were monitored for frequency of recurring content as well as for the introduction of novel content. Language of presentation was also tracked and recorded. In-depth analysis of keywords and metadata may still be undertaken at some point, but cursory analysis was carried out at the time of data collection and noticeable trends were reported to all investigators. Type of video production was also tracked by assigning one of six categories for educational subject area and (if academic in nature) 
one of thirteen academic categories. Primary data collection was completed using strict guidelines for formatting, collection, and assignment to ensure accuracy and consistency across all categories. A direct link to the video entry was also cataloged to ensure quick access to materials for further evaluation.

After the preliminary observation period, a classification system was developed for video content using the following six categories:

(1) Academically-oriented presentations (e.g. an instructor's in-classroom presentation).

(2) Public relations materials (e.g. a college's homecoming event).

(3) Special events (e.g. a keynote speaker at a campus-wide event).

(4) Student orientation (e.g. a college's first-year experience video).

(5) Student-created materials (e.g. a student's assignment for a class).

(6) Professor's response (e.g. an instructor's Q\&A section).

\section{Results}

Research question \#1: what are the characteristics of the most-viewed videos at YouTubeEDU?

Regarding the contents of the most-viewed videos, initially the public relations videos were the most popular category on the monthly list from August 2010 to March 2011 (Figure 1). However, the academically-oriented videos were more popular from April to July 2011. The academically-oriented videos even hit the 50 percent mark in July 2011. By contrast, the academically-oriented videos were always popular (between 40 and 50 percent) in the "all time" most-viewed videos category (Figure 2).

\section{YouTube EDU Totals from Each Month}

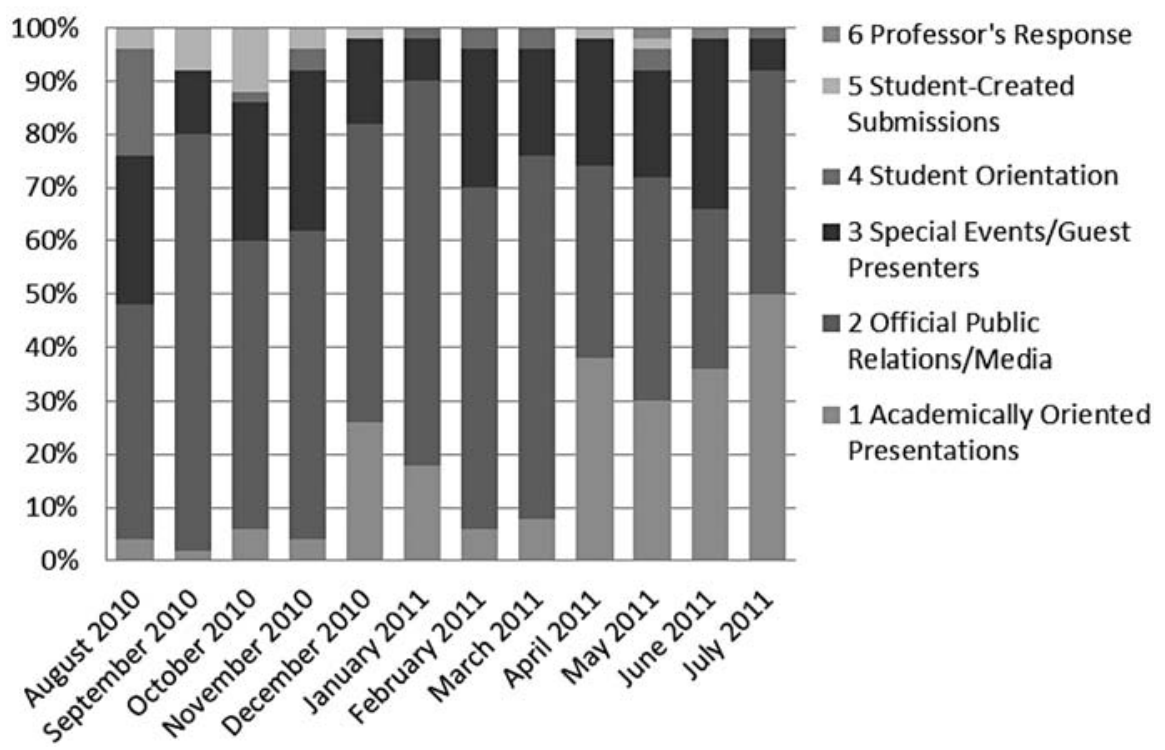

Online access to higher education
Figure 1. Each month's most-viewed videos from all disciplines 


\section{NLW}

$114,3 / 4$

104

Figure 2.

"All time" monthly most-viewed videos from all disciplines

\section{YouTube EDU Totals from All Time}

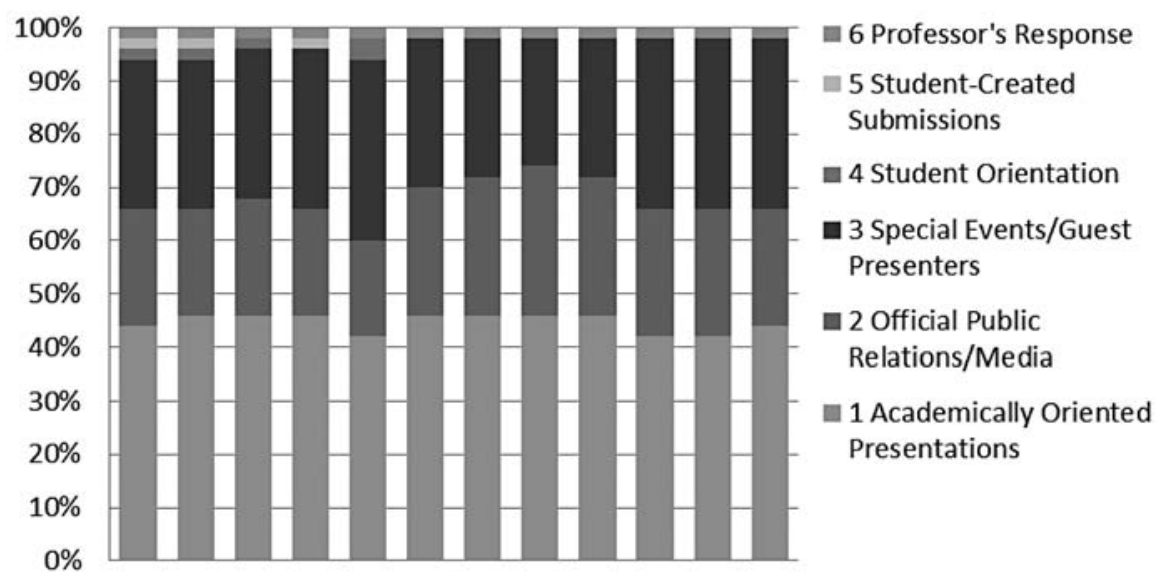

Videos that were part of a series often appeared in the top 50 videos; Harvard's series on law and morality remained popular throughout the study period. Berklee School of Music produced music tutorials that also remained popular. About halfway through the data collection, another noticeable trend began to emerge Khan Academy began to appear in the results. Although focused primarily on basic explanations of science, technology, engineering, and maths (STEM) concepts, Khan Academy videos were watched frequently. Popular consumption seems to have created "superstar" videos that led to increased attention for other videos in the same series.

Regarding the language of the videos, English was the dominant language used by the videos from the monthly most-viewed list. Of total 600 video clips, 583 were in English, one was in Hebrew, six were in Spanish, seven were in Russian, two were in Italian, and one was in French.

Research question \#2: what are the subject and disciplinary distributions of the most-viewed videos?

After characterizing the contents of the most-viewed videos, the authors focused more closely on the academically-oriented videos. Reviewing the "all time" most-viewed videos, the top disciplines were "fine arts and design" (total: 81); "science" (79); "mathematics" (25); "health and medicine" (24); and "engineering" tied with "humanities" (both 23). Regarding the monthly most-viewed videos, the top disciplines were "science" (total: 43); "mathematics" (29); "history" (17); and "business" (10). Those total numbers were observed from August 1, 2010 to July 1, 2011. 


\section{Discussion}

After much review of the website, it was found that YouTubeEDU is loosely organized and that ease-of-access to top videos is not promoted by the current webpage configuration.

New formatting and classification

YouTubeEDU began to offer differently-organized modules of learning to online users in July of 2011. Prior to this date, videos were arranged by popularity within several categories and according to the number of views. It is too soon to determine the effects of this rearrangement on usage and access, yet the authors speculate that this change reflects an increase in casual scholarly usage. Additionally, the initial research has found that YouTubeEDU appears to have no noticeable collection development policy or set organizational structure (Chen and Gilchrist, 2011). The metadata created by the contributing institutions is not part of a controlled vocabulary, so items are often incorrectly categorized. This may account for the lack of attention that YouTubeEDU has received in scholarly investigations.

\section{Academically-oriented video production is limited}

Another issue seems to be that universities and educational institutions that contribute to the creation of YouTubeEDU videos create a small number of academically-oriented videos. The majority of the contributions fall into public relations, entertainment, or student creations. This study examined the currently available educational videos and the usage and collection of those videos. Analysis of these videos within a library science framework is valuable to the development of the YouTube EDU project.

\section{YouTubeEDU promotes casual learning}

During data collection for the research, two resources stood out from the rest. Berklee College of Music produces short YouTubeEDU videos that teach casual learners how to "play a classic rock guitar solo," for example. Berklee videos remained in the top fifty videos of all time throughout the data collection. Halfway through the data collection, Khan Academy entered the top fifty videos. Khan Academy has created short, scaffolded, tutorials for math and science students. The founder was featured on TED and received funding from Microsoft. YouTubeEDU allows casual learners to find information that is reviewed and supported by institutions of higher education. Chelliah and Clarke (2011) argue that the traditional model of knowledge consumption has shifted to a new model of knowledge production. Many of the same institutions that contribute to YouTube EDU are also part of the OpenCourseWare Consortium, a group promoting the dissemination of valid knowledge throughout the world (Kamenetz, 2010). Although casual students are the primary consumers of these YouTubeEDU videos, their usage promotes knowledge production as more people gravitate toward social media.

Videos at TED-Ed

Based on the results gathered from the YouTubeEDU project, the authors plan to utilize the same research approach to collect data from the TED-Ed site. Currently, TED-Ed organizes videos under nine disciplines. TED-Ed also introduces one unique concept: "flip." According to TED-Ed, the term "flip" suggests that teachers from all
Online access to higher education 
NLW

$114,3 / 4$

106 levels disseminate the video to a wider audience. Additionally, "flip" is also a reference to a nascent and evolving teaching method called "flip teaching" (TED-Ed., 2012).

The authors plan to observe the number of videos and flips under each discipline to see how TED-Ed viewers utilize these particular open-access online videos. Crossover between Ted-Ed, Khan Academy, Google, and YouTube is a common occurrence that will continue to effect production and consumption of online educational videos. At this point, YouTubeEDU continues to be less-promoted and ranks low on the radar in academic institutions (except for self-promotion). Ted-Ed has benefited from the popularity of TED videos and from an easy-to-navigate format. Google seems to be involved behind the scenes in both instances; the copyright victories associated with Google Books may impact the services of both entities. Khan Academy appears to be poised for adoption into K-12 classrooms; as the Common Core standards are applied at this level, the concepts and technology associated with this online learning tool will become more sought after.

\section{Conclusions}

In order to further develop the potential of social media learning applications such as YouTubeEDU, we must be willing to apply current teaching methodologies and to evaluate evidence-based outcomes. Although Cao and Hong (2011), Chelliah and Clarke (2011), Kamenetz (2010), and others have mentioned the possibilities of improving online social media, serious research into the potential and consequences of this technology has not been attempted. Universities promote peer review and validate information; the internet promotes information production without validation. As students blaze a trail through this information jungle, YouTubeEDU and other social media applications created by institutions of higher education will serve as accurate guideposts and as checkpoints for the online scholar.

Additionally, the distinction between learning and entertainment will continue to be blurred. YouTubeEDU will need to highlight the academic capabilities of their contributors by creating a dedicated, clearly organized, website for academic content. Online content seems to be best suited to scholars with some background knowledge in the subject. Tapping into human curiosity and our quest for information will promote both the YouTube site and the intellectual capital of our communities. YouTubeEDU will continue to be a peripheral asset to any massively open online course (MOOC) until the authors' recommendations are taken into account. Librarians and other educators at all levels are actively seeking prepared, freely available content for online and in-person courses. YouTubeEDU, and other websites like it, have the opportunity to take the lead in the creation and promotion of online content for all online learners. Change is inevitable; the most flexible and well-promoted tool will withstand the test of time.

\section{References}

Andrews, D.H. and Goodson, L.A. (2011), "A comparative analysis of models of instructional design", in Anglin, G.J. (Ed.), Instructional Technology: Past, Present, and Future, 3rd ed., Libraries Unlimited, Santa Barbara, CA, pp. 205-25.

Bonk, C. (2009), The World is Open: How Web Technology is Revolutionizing Education, Jossey-Bass, San Francisco, CA. 
Cao, Y. and Hong, P. (2011), “Antecedents and consequences of social media utilization in college teaching: a proposed model with mixed-methods investigation", On the Horizon, Vol. 19 No. 4, pp. 297-306.

Chelliah, J. and Clarke, E. (2011), "Collaborative teaching and learning: overcoming the digital divide?”, On the Horizon, Vol. 19 No. 4, pp. 276-85.

Chen, H. and Gilchrist, S.B. (2011), "Higher education e-learning and YouTube EDU: a LIS collection development approach", paper presented at the 3rd International Conference on Qualitative and Quantitative Methods in Libraries, Athens, Greece.

Gauntlett, D. (2011), Making is Connecting: The Social Meaning of Creativity, From DIY and Knitting to YouTube and Web 2.0, Polity Press, Cambridge.

Gregory, V.L. (2011), Collection Development and Management for 21st Century Library Collections: An Introduction, Neal-Schuman Publishers, New York, NY.

Hirumi, A. and Kidney, G. (2011), "Contemporary issues facing distance educators”, in Anglin, G.J. (Ed.), Instructional Technology: Past, Present, and Future, 3rd ed., Libraries Unlimited, Santa Barbara, CA, pp. 145-60.

Kamenetz, A. (2010), DIY U: Edupunks, Edupreneurs and the Coming Transformation of Higher Education, Chelsea Green, White River Junction, VT.

Kincaid, J. (2010), "YouTubeEDU finished its freshman year with 300 university partners in tow", TechCrunch, 7 February, available at: http://techcrunch.com/2010/03/25/youtubeedu-stats/

Lange, P.G. (2012), "Doing it yourself with others", New Media \& Society, Vol. 14 No. 3, pp. 533-8.

Lerman, S.R. and Miyagawa, S. (2003), "Open course ware: a case study in institutional decision making”, available at: http://web.mit.edu/miyagawa/www/pdfs/Academe $\% 20$ Sept-Oct $\%$ 202002.pdf (accessed 30 May 2012).

Leung, L. (2009), "User-generated content on the internet: an examination of gratifications, civic engagement and psychological empowerment”, New Media \& Society, Vol. 11 No. 8, pp. 1327-47.

Lewin, T. (2011a), “A short-lived test, even with coaching”, The New York Times, 25 August, available at: www.nytimes.com/2011/08/25/education/25futureside.html

Lewin, T. (2011b), “A way to speed the pace”, The New York Times, 25 August, available at: www.nytimes.com/2011/08/25/education/25future_straight.html

Lewin, T. (2011c), “Online enterprises gain foothold as path to a college degree”, The New York Times, 25 August, available at: www.nytimes.com/2011/08/25/education/25future.html

Lewin, T. (2011d), “Open courses, nearly free”, The New York Times, 25 August, available at: www.nytimes.com/2011/08/25/education/25future_people.html

Lewin, T. (2011e), "Weekly prompts from a mentor", The New York Times, 25 August, available at: www.nytimes.com/2011/08/25/education/25future_WGU.html

Lyons, L.E. (2010), "Collection evaluation: selecting the right tools and methods for your library", in Orcutt, D. (Ed.), Library Data: Empowering Practice and Persuasion, Libraries Unlimited, Santa Barbara, CA, pp. 37-51.

Markoff, J. (2012), "Online education venture lures cash infusion and deals with 5 top universities", available at: www.nytimes.com/2012/04/18/technology/coursera-plans-toannounce-university-partners-for-online-classes.html?_r=1 (accessed 24 April 2012).

MIT OpenCourseWare (2012), available at: http:/ocw.mit.edu/index.htm (accessed 20 March 2012). 
NLW

$114,3 / 4$

108

Orcutt, D. (Ed.) (2010), Library Data: Empowering Practice and Persuasion, Libraries Unlimited, Santa Barbara, CA.

Schiffman, S.S. (2011), "Instructional systems design: five views of the field”, in Anglin, G.J. (Ed.), Instructional Technology: Past, Present, and Future, Libraries Unlimited, Santa Barbara, CA, pp. 191-204.

Strom, S. (2012), "YouTube subtracts racy and raucous to add a teaching tool", The New York Times, 14 March, available at: www.nytimes.com/2012/03/10/education/youtube-finds-away-off-schools-banned-list.html?_r=1\&scp=1\&sq=YouTubeEDU\&st=cse

TED-Ed. (2012), available at: http://ed.ted.com (accessed 25 April 2012).

\section{Further reading}

Bossu, C. and Tynan, B. (2011), "OERs: new media on the learning landscape”, On the Horizon, Vol. 19 No. 4, pp. 259-67.

Carney, S., Koufogiannakis, D. and Ryan, P. (2004), "Library services for users of personal digital assistants: a needs assessment and program evaluation”, portal: Libraries and the Academy, Vol. 4 No. 3, pp. 393-406.

Covey, N. (2010), “Changing models: a global perspective on paying for content online", nielsenwire, 16 February, available at: http://blog.nielsen.com/nielsenwire/global/ changing-models-a-global-perspective-on-paying-for-content-online/

Eubanks, D. (2011), "A survey of attitudes about methods of assessment", Assessment Update: Progress, Trends, and Practices in Higher Education, Vol. 23 No. 3, pp. 1-15.

Guerlac, S. (2011), "Humanities 2.0: e-learning in the digital world", Representations, Vol. 116 No. 1, pp. 102-27.

Hew, K.F. (2011), "Review: students' and teachers' use of Facebook”, Computers in Human Behavior, Vol. 27, pp. 662-76.

Keller, B. (2011), "The university of wherever", The New York Times, 2 October, available at: www.nytimes.com/2011/10/03/opinion/the-university-of-wherever.html

Martin, C. (2011), "An information literacy perspective on learning and new media”, On the Horizon, Vol. 19 No. 4, pp. 268-75.

(The) New York Times (2011), "Learning counts: receiving credit for job experience”, 25 August, available at: www.nytimes.com/2011/08/25/education/25future_learning.html

OECD (2007), Giving Knowledge for Free: The Emergence of Open Educational Resources, OECD Publishing, Paris.

Parry, M. (2011), "Online education is everywhere. What's the next big thing?”, The Chronicle of Higher Education, 31 August, available at: http:/chronicle.com/blogs/wiredcampus/ online-education-is-everywhere-whats-the-next-big-thing/32898

US Fed News Service, Including US State News (2011), "Young University of Houston entrepreneurs and students pay tribute to Steve Jobs", 12 October, available at: http://ulib. iupui.edu/cgi-bin/proxy.pl?url=/docview/898411772?accountid=7398

van Dijk, J. and Hacker, K. (2003), "The digital divide as a complex and dynamic phenomenon”, The Information Society, Vol. 19 No. 4, pp. 315-26.

Williams, G. (2011), "How to measure (and improve) students' digital skills?”, The Chronicle of Higher Education, 14 September, available at: http://chronicle.com/blogs/profhacker/howto-measure-and-improve-students-digital-skills/35636 
Wiseman, R. (2011), "Top 10 YouTube videos posted by colleges, and what they mean”, The Chronicle of Higher Education, 5 July, available at: http://chronicle.com/blogs/ wiredcampus/top-10-youtube-videos-posted-by-colleges-and-what-they-mean/32070
Online access to higher education

\begin{abstract}
About the authors
Hsin-liang Chen is an Associate Professor at the School of Library and Information Science, Indiana University - Indianapolis. His research interests center on the applications of information and communication technologies (ICTs) to assist users in accessing and using information in different environments. Hsin-liang Chen is the corresponding author and can be contacted at: chenhsin@iupui.edu

Sarah Burns Gilchrist is now a Research and Instruction Librarian for Education at Towson University. Her research interests concern access to information; student-centered teaching and learning; and the use of new technology to enhance global understanding.
\end{abstract}

